\title{
Spectroscopic Analysis of a Theropod Dinosaur (Reptilia, Archosauria) from the Ipubi Formation, Araripe Basin, Northeastern Brazil
}

\author{
João Hermínio da Silva, ${ }^{1}$ Francisco Eduardo de Sousa Filho, ${ }^{2}$ Antônio Álamo Feitosa Saraiva, ${ }^{3}$ \\ Nádia Amanda Andrade, ${ }^{3}$ Bartolomeu Cruz Viana, ${ }^{4}$ Juliana Manso Sayão, ${ }^{5}$ Bruno Tavares de \\ Oliveira Abagaro, ${ }^{6}$ Paulo de Tarso Cavalcante Freire, ${ }^{6}$ and Gilberto Dantas Saraiva ${ }^{7}$ \\ ${ }^{1}$ Universidade Federal do Ceará, Campus do Cariri, 63000-000 Juazeiro do Norte, CE, Brazil \\ ${ }^{2}$ Departamento de Física, Universidade Regional do Cariri, 63100-100 Crato, CE, Brazil \\ ${ }^{3}$ Departamento de Ciências Biológicas, Universidade Regional do Cariri, 63100-100 Crato, CE, Brazil \\ ${ }^{4}$ Departamento de Física, Universidade Federal do Piauí, 64049-550 Teresina, PI, Brazil \\ ${ }^{5}$ Núcleo de Biologia, Centro Acadêmico de Vitória, Universidade Federal de Pernambuco, 55608-680 Vitória de Santo Antão, PE, Brazil \\ ${ }^{6}$ Departamento de Física, Universidade Federal do Ceará, 604455-760 Fortaleza, CE, Brazil \\ ${ }^{7}$ Faculdade de Educação Ciências e Letras do Sertão Central, Universidade Estadual do Ceará, 63900-000 Quixadá, CE, Brazil
}

Correspondence should be addressed to Gilberto Dantas Saraiva; gilberto@fisica.ufc.br

Received 20 June 2012; Revised 3 August 2012; Accepted 17 August 2012

Academic Editor: Kong-Thon Tsen

Copyright (C) 2013 João Hermínio da Silva et al. This is an open access article distributed under the Creative Commons Attribution License, which permits unrestricted use, distribution, and reproduction in any medium, provided the original work is properly cited.

\begin{abstract}
The Araripe Sedimentary Basin is known by the excellence of its fossils, regarding the preservation, diversity, and quantity. Here, we present a spectroscopic analysis using several experimental techniques (X-ray energy dispersion spectroscopy, Fourier-transform infrared spectroscopy) as well as X-ray diffraction and thermogravimetric analysis applied in small fragments of bones from the posterior members of a theropod dinosaur. The results agree regarding the different composition of the stone matrix and the fossilized bone, indicating a partial substitution of the material by elements present in the depositional environment. However, differently from what is believed to occur, there is evidence that pyritization is not the only mechanism of fossilization for a specimen of Ipubi formation, but calcification, additionally, plays an important role in the fossil production of this Formation.
\end{abstract}

\section{Introduction}

The geological process of sedimentation, which has happened throughout millions of years, can include the preservation of animal and vegetal specimens from ancient times under the form of fossils [1]. The occurrence of this process involves a series of chemical events, many not yet completely understood. For the fossil preservation, for example, it is known that total or partial alteration of its chemical composition is verified. Some of the most important processes include the dissolution and removal of mineralized material by the interstitial waters which seep into the bone and replace the chemicals with rock-like minerals. The process of fossilization involves dissolving and replacing the originals minerals in the object (such as hydroxyapatite) with other minerals (such as calcite) [1]. In alkaline regions, the dissolution of the silicon dioxide is more probable to occur, while in regions highly acidic, the dissolution of the calcium carbonate it is supposed to happen. Diverse processes can be associated with different regions, but even in only one region it is possible to be associated with many mechanisms of fossilization $[2,3]$.

In the Brazilian depositional scenario the Araripe Sedimentary Basin is one of the localities where different fossilization processes act. Located among the states of Ceará, Pernambuco, and Piauí, at the northeast of Brazil, it comprises around $12,000 \mathrm{~km}^{2}$, and it is considered the largest interior northeastern sedimentary basin [4]. From a geological point of view, Araripe Basin is formed by four main stratigraphic 
sequences [4]: (i) a Paleozoic sequence composed of the Cariri formation; (ii) a Juro-Neocomian sequence composed of Brejo Santo, Missão Velha, and Abaiara formations; (iii) an Aptian-Albian sequence composed of the Rio da Batateira, Crato, Ipubi and Romualdo formations (Santana Group); (iv) an Albian-Cenomanian sequence composed of the Exu Formation. In particular, for the Ipubi and Romualdo Formations, they were characterized by short-lived sea ingression, which has deposited extensive gypsum beds (in Ipubi formation) and fossiliferous carbonate concretions. In the Araripe Basin, sediments of the Cretaceous period were deposited throughout almost 50 million years, and a diversity of sedimentary rocks such as laminated limestones, gypsite benches, shales and fine sandstones have been found [5]. Among the stratigraphic layers of the Araripe Sedimentary Basin, there is the Ipubi Formation. This geological unit represents the evaporitic face of the Aptian-Albian lacustrine system. It is primarily composed of gypsite and anhydrite deposits interbed by dark lutites [5]. Although Ipubi formation presents several species of fossils, the fossilization mechanism from this formation is poorly understood. Just a few aspects have been discussed in the literature, and only a few fossil specimen studies have been published such as on fishes, on turtles and on microfossils [4]. This differs from the knowledge about the fossils from the Santana Formation, the superior unity of the basin that is more extensive than Ipubi [6-13]. Some works [6,7] emphasize the absence of specific geochemistral studies in order to make greater inferences about the deposition process, precipitation and origin of its sediments. However a possible lacustrine origin for these deposits is proposed. With the objective to help the paleoenvironmental interpretations, and to better understand the depositional extracts of this area, we present a spectroscopic characterization of fossilized bone fragments of a theropod dinosaur, specie in paleontological description process, found in the Ipubi Formation. Dinosaur fossils were rarely reported in Araripe Basin until now. Only four dinosaurs were found in superior levels of the Romualdo formation ( $40 \mathrm{~m}$ above of Ipubi). With the use of X-ray diffraction techniques (XRD), Fourier-transform infrared spectroscopy (FTIR), X-ray energy dispersion spectroscopy (EDS) and thermogravimetric analysis (TG), very sensitive techniques for characterizing samples in little amounts, we gained insights about this problem.

On one hand, the Ipubi formation is the most important lithostratigraphic unit of the Cariri region. From this unit it is extracted around $96 \%$ of the total calcium sulfate consumed in Brazil. Such an extraction produces a series of environmental waste that degrades the regional freshwater resources. On the other hand, renewable freshwater issues are one of the great challenges that several countries, in particular developing ones, are facing since in the beinning of the century. Araripe Basin is a rich source of groundwater, and the understanding of the processes that produce it (including the formation of the basin itself and other issues related to it such as the origin of the fossils and the origin of the water sources) is fundamental to obtain a unified picture of the Araripe Basin. Our work tries to fill a gap in the understanding of one of these aspects, that is, the richness of processes that originate fossils and the stratigraphic layer of Ipubi formation of Araripe Basin.

\section{Experimental Details}

2.1. Material. The material (fossil and matrix stone) was collected from residues of the mine called Conceição Preta, in an exploration area of the calcium sulfate close to the city of Santana do Cariri (Ceará, Brazil). The fossil was obtained in a systematic collective work performed by the authors. The material is cleaned in order to left fossil without the sediments that involved it (Table 1).

In Figures 1(a) and 1(b) we present the localization of Araripe Basin, and in Figure 1(c) we present the localization of Conceição Preta mine, where the sample was collected. The sedimentary matrix is dark-gray laminate, pyrobituminous shale, from the level just above the gypsum bed (evaporite). On this level, we can observe many fossil impressions of fishes and plants, as described by Saraiva et al. [8]. With those, it was observed the occurrence of compressed and articulated bones from the posterior member of a theropod dinosaur. The complete fossil (a part of the dinosaur femur) measured $1.8 \mathrm{~m}$ and the characteristic fingers allowed us to classify it as a theropod. Figures $1(\mathrm{~d})$ and 1(e) present a representation of the theropod dinosaur and a picture of the sample. Fossil femur fragments that broke off were used for chemical characterizations. Small fragments of this material were pulverized for the chemical characterization, and the same procedure was used for the matrix which involved the fossil.

2.2. X-Ray Diffraction (DRX). The X-ray diffraction measurements were done at the Physics Department of the Universidade Federal do Ceará (UFC) utilizing a Rigaku equipment, model DMAXB, with the Bragg-Brentano focal geometry. We have used the scanning step of $1^{\circ}$ by minute for each sample.

\subsection{Fourier-Transform Infrared Spectroscopy (FTIR). The} measurements of FTIR were done in the Physics Department of the UFC with a Bruker spectrometer, model Vertex 70 . The spectral region analyzed spanned from 400 up to $4000 \mathrm{~cm}^{-1}$. The samples were mixed with $\mathrm{KBr}$ at $1: 100$ ratio and pressed in laminated form. The transmittance technique was used in the measurements.

2.4. X-Ray Energy Dispersion Spectroscopy (EDS). The EDS spectra were obtained through a Bruker spectrometer, model Xflash, attached to a TESCAN scanning electronic microscope, model Vega XMU. The measurements were performed under vacuum and the analyzed region from 0 up to $40 \mathrm{keV}$, with energy of electron acceleration of $30 \mathrm{KV}$.

2.5. Thermogravimetric Analysis (TG). The thermogravimetric curves of the fossil and the matrix stone were obtained using an equipment of Netzsch, model STA $409^{\circ} \mathrm{C}$. The samples were scanned in the temperature interval between 
TABLE 1: Infrared main bands and tentative assignments of the main infrared bands of the fossil and the matrix stone [14-16].

\begin{tabular}{|c|c|c|c|c|}
\hline Band & Fossil $\left(\mathrm{cm}^{-1}\right)$ & Assignment-Fossil & Matrix $\left(\mathrm{cm}^{-1}\right)$ & Assignment-Matrix Stone \\
\hline 1 & 470 & Asymmetric $\mathrm{PO}_{4}{ }^{3-}$ deformation & 469 & Asymmetric $\mathrm{PO}_{4}{ }^{3-}$ deformation \\
\hline 2 & 565 & Asymmetric $\mathrm{PO}_{4}{ }^{3-}$ deformation & 525 & - \\
\hline 3 & 604 & Asymmetric $\mathrm{PO}_{4}{ }^{3-}$ deformation & 570 & Asymmetric $\mathrm{PO}_{4}{ }^{3-}$ deformation \\
\hline 4 & 866 & Asymmetric $\mathrm{CO}_{3}{ }^{2-}$ deformation & 605 & Asymmetric $\mathrm{PO}_{4}{ }^{3-}$ deformation \\
\hline 5 & 960 & Symmetric $\mathrm{PO}_{4}{ }^{3-}$ stretching & 710 & Symmetric $\mathrm{CO}_{3}{ }^{2-}$ deformation \\
\hline 6 & 1041 & Asymmetric $\mathrm{PO}_{4}{ }^{3-}$ stretching & 870 & Asymmetric $\mathrm{CO}_{3}{ }^{2-}$ deformation \\
\hline 7 & 1425 & Asymmetric $\mathrm{CO}_{3}{ }^{2-}$ stretching & 1040 & Asymmetric $\mathrm{PO}_{4}{ }^{3-}$ stretching \\
\hline 8 & 1457 & Asymmetric $\mathrm{CO}_{3}{ }^{2-}$ stretching & 1430 & Asymmetric $\mathrm{CO}_{3}{ }^{2-}$ stretching \\
\hline
\end{tabular}

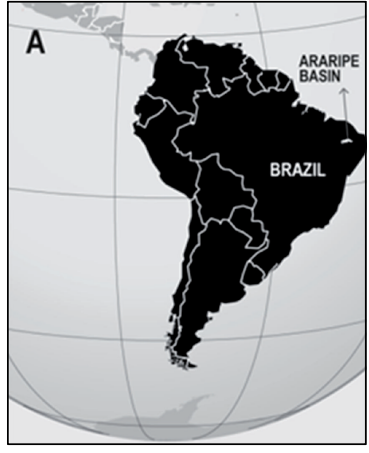

(a)

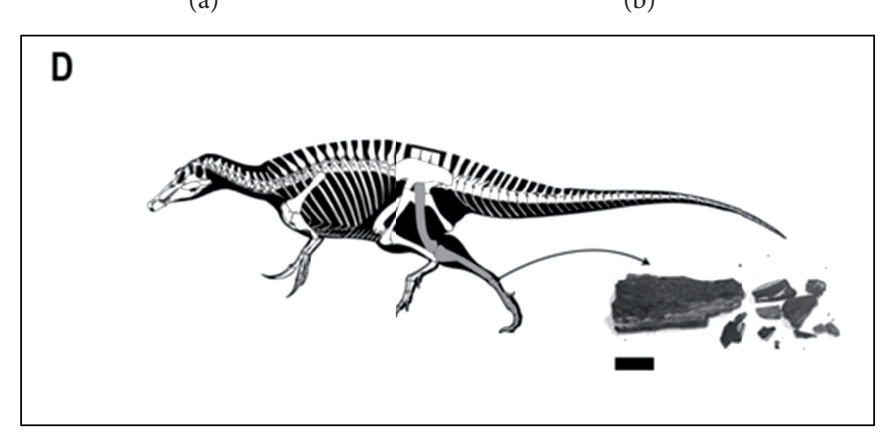

(d)

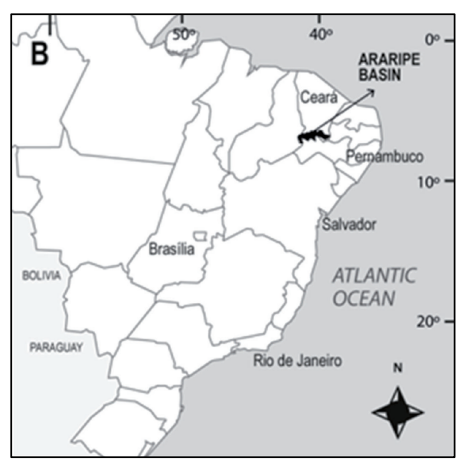

(b)

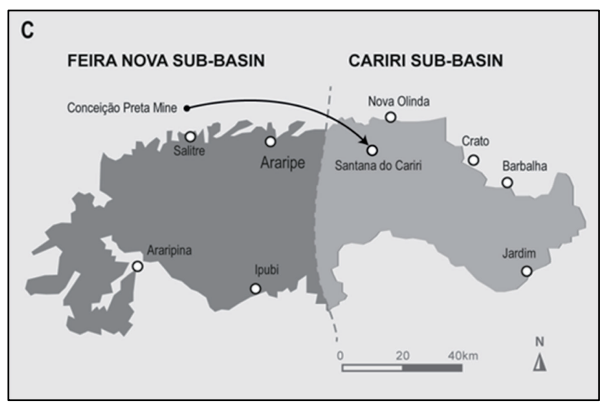

(c)

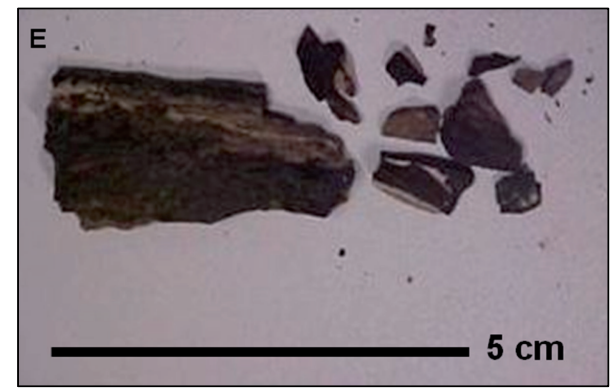

(e)

Figure 1: Localization of Araripe Basin in South America (a) and in Brazil (b). Map of Araripe Basin showing the localization of Conceição Preta Mine, in the Santana do Cariri city (c). Schematic view of the dinosaur (d) and picture of the part of the bone of the leg studied in this work (e).

30 and $1300^{\circ} \mathrm{C}$ with a warming rate of $10^{\circ} \mathrm{C} / \mathrm{min}$ in nitrogen atmosphere.

\section{Results and Discussion}

The qualitative chemical composition of the samples was studied by EDS. In Figure 2 (top panel), we present the EDS spectrum of the fossil, which clearly shows the presence of $\mathrm{Ca}, \mathrm{P}, \mathrm{O}$, and $\mathrm{C}$. Besides these elements, which are the formers of the hydroxyapatite carbonate, it is possible to observe the presence of $\mathrm{S}, \mathrm{Na}$, and $\mathrm{Fe}$ in minor quantities, maybe indicating the presence of pyrite. The presence of these elements can be understood as the occurrence of an average distribution of the chemical contents of elements, which were in the hard parts of the dinosaur body. It must be noted the long period of time (estimated as at least 1 million years), which this material was in a water environment (these fossils are dated by Aptian-Albian period and they are approximately 105 million years old); a favorable condition to the substitution process of the original content of the animal remains. Minerals with high quantity of $\mathrm{Na}, \mathrm{S}$, and $\mathrm{Fe}$ are common in evaporite deposits originated in water bodies under marine influence, or with salinity moderate to high (similar to a river or lake close to the ocean, as a lake fed by broad deltas). Figure 2 (right panel) shows the EDS spectrum of the sedimentary matrix. It is possible to observe the elements $\mathrm{Ca}, \mathrm{C}$, and $\mathrm{O}$ in greater quantities, which are related to the calcite structure, according to the $\mathrm{X}$ ray diffraction analysis. It is also possible to identify in smaller quantities $\mathrm{Fe}, \mathrm{S}, \mathrm{Si}, \mathrm{Al}, \mathrm{P}, \mathrm{K}$, and $\mathrm{Mg}$. The presence of traces of these elements can be explained due to the material that 


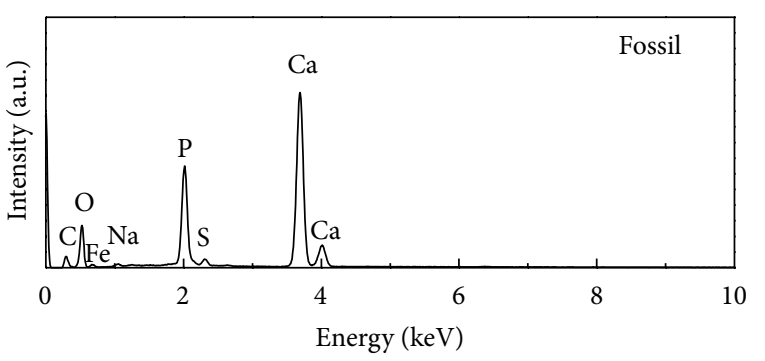

(a)

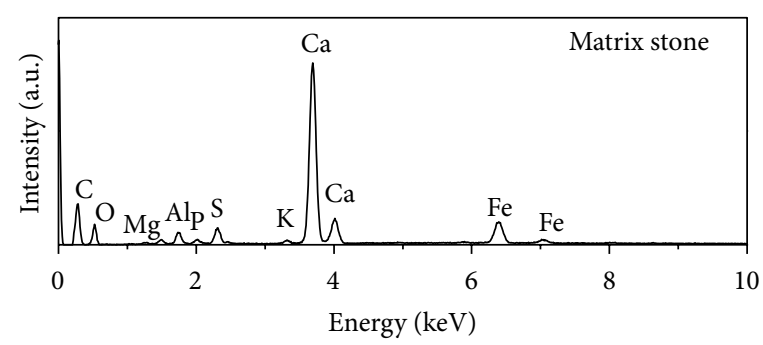

(b)

FIGURE 2: X-ray energy dispersion spectrum (EDS) of the fossil (left curve) and X-ray energy dispersion spectrum (EDS) of the sedimentary matrix stone (right curve).

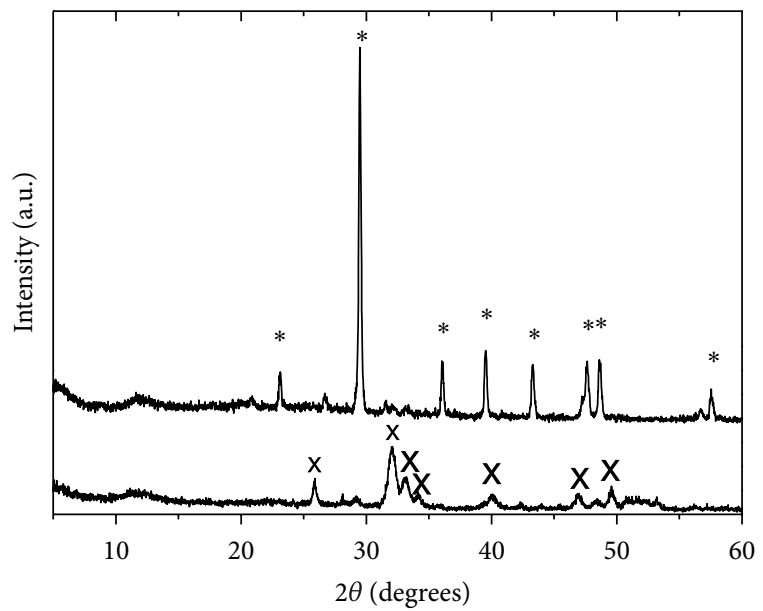

FIGURE 3: X-ray diffractogram of the fossil (bottom curve) and of the matrix (upper curve). The hydroxyapatite and calcite phases are marked as $\mathrm{X}$ and ${ }^{*}$, respectively.

originated from the precipitation in an anoxic environment around the fossilized specimen and also to waters with high temperatures.

Figure 3 shows the X-ray diffractogram of the fossil and the stone matrix. The fossil difractogram shows peaks that can be identified as crystalline planes of the phosphate phase of the calcium hydroxide or calcium hydroxyapatite $\left(\mathrm{Ca}_{10}\left(\mathrm{PO}_{4}\right)_{6}(\mathrm{OH})_{2}\right)$. As a consequence, it is possible to assume that the hydroxyapatite is the really predominant phase in the fossil ${ }^{14}$, as occurs in the bones of living animals (where hydroxyapatite is the major constituent). The width of the fossil diffraction peaks shows that it possess a low crystallinity. In the X-ray difractogram of the matrix, we were able to identify a great amount of peaks related to the crystalline phase of calcium carbonate or calcite, $\mathrm{CaCO}_{3}$ $[9,17,18]$. Using the X-ray diffractogram it is possible to assume that the predominant crystalline phase in the fossil is phosphate of hydroxide calcium and in the matrix is calcite. A similar situation also happens in the Romualdo Formation concretions, the upper level of the Santana Group. The Xray difractogram also shows traces of calcite in the fossil and hydroxyapatite in the matrix. After these results, in order to enhance the analysis, it was decided that an infrared spectroscopic investigation should be performed to detect these traces and confirm the results obtained by the X-ray diffraction measurements.

The fossil and its matrix infrared spectra are shown in Figure 4. Regarding the FTIR spectrum of the fossil we observe the most intense modes located close to 565,604 , 960 and $1041 \mathrm{~cm}^{-1}$, which are related to the vibrations of the phosphate ion $\left(\mathrm{PO}_{4}{ }^{3-}\right)$. At small intensity, in the fossil spectrum, there is also the presence of modes in the region of 866,1425 and $1457 \mathrm{~cm}^{-1}$, which are related to the vibrations of carbonate ions [14, 19]. Besides these, it is possible to observe a mode close to $470 \mathrm{~cm}^{-1}$, which can be related to the net vibration of the ionic interaction calcium-phosphate. In the spectrum of the matrix sample, the most intense modes are located close to 870 and $1430 \mathrm{~cm}^{-1}$, which are related to $\mathrm{CO}_{3}$ group. Modes with smaller intensity appear around 570, 710 , and $1040 \mathrm{~cm}^{-1}$, which are related to the vibrations of the ion phosphate vibration, to the groupings $\mathrm{HCO}_{3}{ }^{2-}$, and $\mathrm{HPO}_{4}{ }^{2-}$ and $\mathrm{PO}_{4}{ }^{3-}$ groups, respectively $[20,21]$. It can also be seen a few modes with even lower intensities that can be related to other organic and inorganic materials which are present in small quantities in the samples. For the fossil the phases intensity relationship between the bands indicates that the dominant phase is the hydroxyapatite. It is well known that there are different apatites with constitutional carbonate ions at different sites. On the matrix we observe that the dominant phase is the calcium carbonate or calcite, with the presence of diverse elements in small concentrations. This mixture can be understood as traces of fossils and others soil elements, which become aggregated to the matrix and viceversa. The presence of $\mathrm{OH}^{-}$ions and water molecules, in a small quantity, adsorbed in the fossil and the stone matrix is identified by the presence of the band around $3600 \mathrm{~cm}^{-1}$ (not shown here) $[9,14,19]$. The infrared spectroscopy results agree with XRD investigation, complementing it with the semiquantitative analysis of the phase mixture in the samples.

The chemical composition measurements agree well with the XRD and FTIR measurements done in this paper, and 


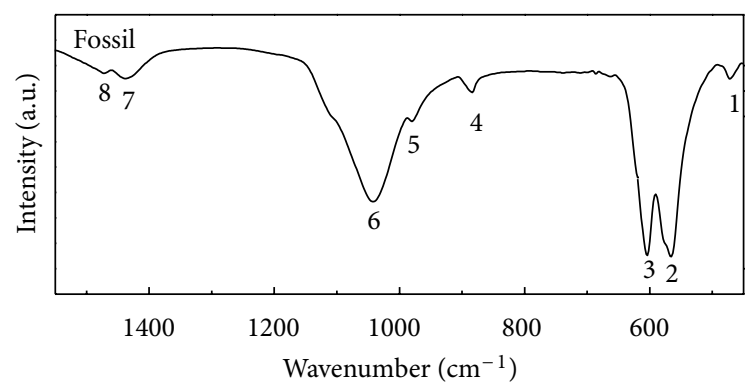

(a)

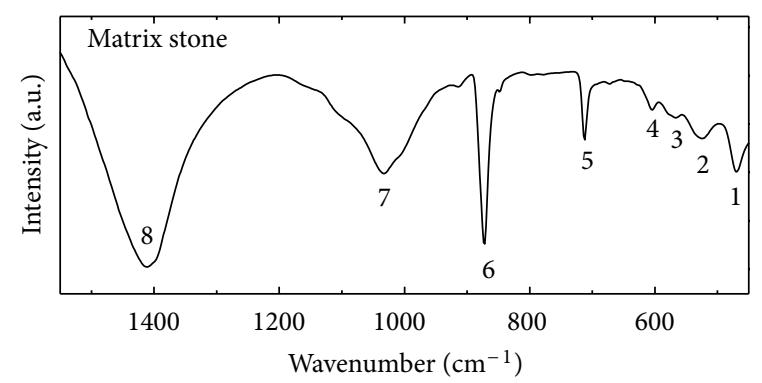

(b)

FIGURE 4: FT-IR spectra of the fossil (left curve) and of the matrix (right curve).

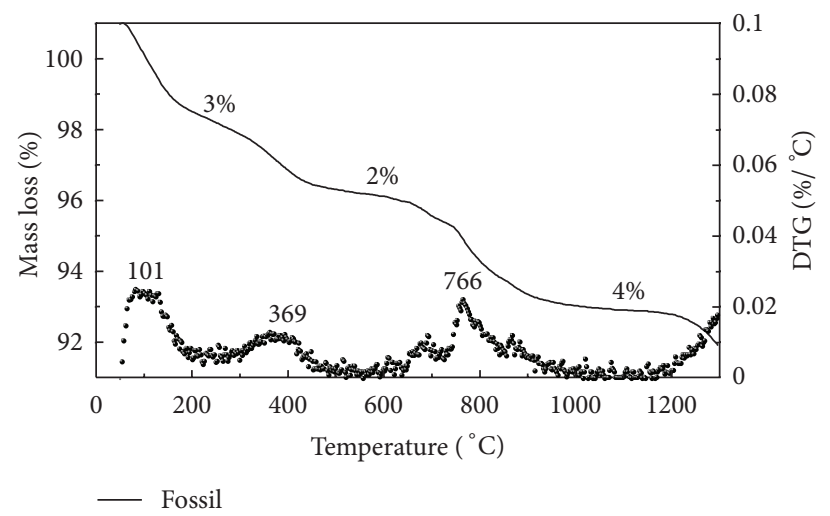

(a)

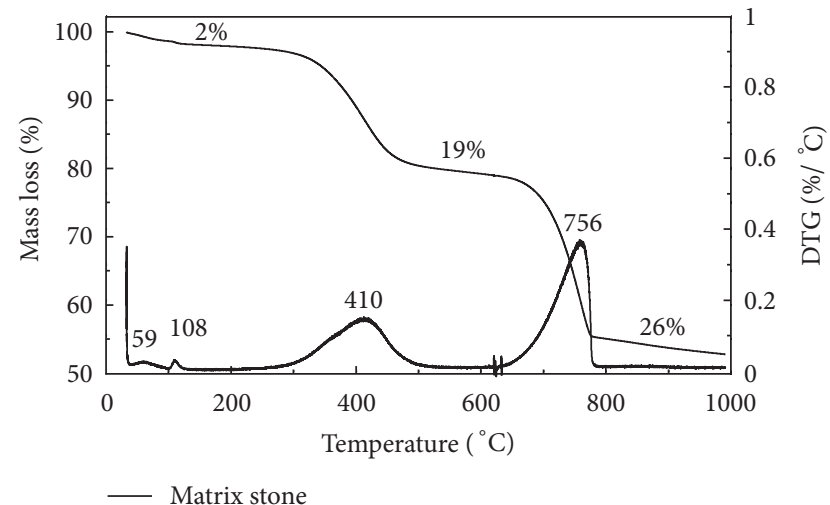

(b)

FIGURE 5: Right panel: matrix stone; left panel: fossil thermogravimetric (TG) and differential TG analysis, with temperature over the peaks associated to thermal events.

besides that, suggest the possible origin of the fossilization. These results point to a partial substitution of the bone, as well as to the existence of not pyritized fossils in the Ipubi formation, as largely cited in the literature [22-24]. The presence of sulfur and iron in considerable quantities is indicative of an anoxide environment around the fossilized material.

Figure 5 shows the TG analysis of the fossil (left panel) and of the matrix stone (right panel). Figure 5(a) shows that in the TG of the fossil, it is possible to observe a mass loss (about $3 \%$ ) around $80^{\circ} \mathrm{C}$ and $101^{\circ} \mathrm{C}$ that is related to the loss of water present in the sample. In a previous study of the vertebral column of the extinct fish, Cladocyclus ferox, the TG analysis showed a change in the region around $90^{\circ} \mathrm{C}$, which was also associated to the water evaporation [25]. It is interesting to notice that in the same work [25], when analyzing the TG curve of a modern vertebrae fish, the quantity of water lost around $80-100^{\circ} \mathrm{C}$ was approximately $6 \%$ higher than both the Cladocyclus ferox fossil and the theropod analyzed here. At higher temperatures (around $369^{\circ} \mathrm{C}$ and $690^{\circ} \mathrm{C}$ ) there is a mass loss due to organic compounds and the phosphate contained in the hydroxyapatite. At $766^{\circ} \mathrm{C}$ another mass loss (about 4\%) can be observed, related to the carbonate from the calcium carbonate originated through the fossilization process. At temperatures higher than $1200^{\circ} \mathrm{C}$, we can infer that starts the decomposition of hydroxyapatite to anhydrous calcium phosphate [15]. The Figure 5(b) shows the thermogravimetric analysis of the matrix. Similar to the fossil, there is a mass loss around $108^{\circ} \mathrm{C}$ related to the free water loss. Around $410^{\circ} \mathrm{C}$, it was observed another loss of mass (about $19 \%$ ) associated to the dehydroxylation of $\mathrm{Ca}(\mathrm{OH})_{2}$ which percolated to the stone matrix. The greatest mass loss (about $26 \%$ ) registered is observed at around $756^{\circ} \mathrm{C}$, being due to the decarbonation. This result of the TG analysis shows that the fossilization process developed in the Ipubi formation fossil allowed the occurrence of diffusion, in reasonable quantities, of material from the fossil to the matrix and vice versa. In a previous study with fossils from the Romualdo Formation, this diffusion was observed in small quantities. As an example, in the study done with coprolites, it was observed a minimal diffusion of material which covered the fossil [10]. Most importantly yet is the fact that in a previous work it was shown that a certain plant fossil, Brachyphyllum castilhoi, was fossilized through a pyritization process [16] in Ipubi formation. The present work shows that calcification is the main mechanism of fossilization of the theropod dinosaur. 
The difference between the two processes should be explained by the fact that Brachyphyllum castilhoi being a plant, it does not produce ammonia and, consequently, does not catalyze calcium ions and carbonates, precluding the formation of calcium carbonate as well known from literature [6].

\section{Conclusions}

With this study it was possible to characterize the composition of a theropod fossil and its involving stone matrix. These materials, fossil and matrix, are predominantly composed of calcium hydroxyapatite $\left(\mathrm{Ca}_{10}\left(\mathrm{PO}_{4}\right)_{6}(\mathrm{OH})_{2}\right)$ and calcite $\left(\mathrm{CaCO}_{3}\right)$, respectively. These main substances substituted the original body organic content, through fossilization mechanisms of mineralization in shales. However, despite that the material is dated by correlation to the Aptian-Albian period, the difference in composition between the stone matrix and the fossilized bone indicates a partial substitution of the fossil material by elements present in the depositional environment. It is evident the conversion of some original elements from the body, mainly the hydroxyapatite, which was the major bone constituent when the dinosaur was still alive. It is also important to notice the absence of pyrite in these analyses, showing the existence of not pyritized fossils in the Ipubi formation in disagreement with the current idea related to these fossils.

\section{Acknowledgments}

Authors thank the support from Brazilian agencies CAPES, $\mathrm{CNPq}$, and FUNCAP. They also acknowledge Dr. J. R. Gonçalves and Mr. F. Watson for the critical reading of the paper.

\section{References}

[1] D. E. G. Briggs and P. R. Crowther, Eds., Palaeobiology II, Blackwell Science, Oxford, UK, 2003.

[2] J. H. Oehler and J. W. Schopf, "Artificial microfossils: experimental studies of permineralization of blue-green algae in silica," Science, vol. 174, no. 4015, pp. 1229-1231, 1971.

[3] J. M. Shopf, "Modes of fossil preservation," Review of Palaeobotany and Palynology, vol. 20, no. 1-2, pp. 27-53, 1975.

[4] M. L. Assine, "Analise estratigrafica da Bacia do Araripe, nordeste do Brasil," Revista Brasileira de Geociências, vol. 22, pp. 289-300, 1992.

[5] M. R. Lima, "Paleontologia da Formação Santana (Cretáceo do nordeste do Brasil): estágio atual de conhecimentos," Anais da Academia Brasileira de Ciências, vol. 51, pp. 545-556, 1979.

[6] J. G. Maisey and S. Fossils, An Illustrated Atlas, TFH Publications, Neptune City, NJ, USA, 1991.

[7] E. A. Menor, V. M. M. Cavalcanti, and R. B. Sena, "Os eventos evaporiticos da formação Santana, bacia do Araripe, Nordeste do Brasil," Revista de Geologia, vol. 6, pp. 93-102, 1993.

[8] A. A. F. Saraiva, M. H. Hessel, N. C. Guerra, and E. Fara, "Concreções calcárias da Formação Santana, Bacia do Araripe: uma proposta de classificação," Estudos Geológicos, vol. 17, no. 1 , pp. $40-57,2007$.
[9] R. J. C. Lima, A. A. F. Saraiva, S. Lanfredi, M. A. D. L. Nobre, P. T. C. Freire, and J. M. Sasaki, "Spectroscopic characterization of a fish of the cretaceous period (Araripe Basin)," Química Nova, vol. 30, no. 1, pp. 22-24, 2007.

[10] R. J. C. Lima, P. T. C. Freire, J. M. Sasaki, A. Á. F. Saraiva, S. Lanfredi, and M. A. D. L. Nobre, "Study of coprolites from the Araripe sedimentary basin through FT-IR spectroscopy and Xray diffraction," Química Nova, vol. 30, no. 8, pp. 1956-1958, 2007.

[11] R. Pereira, I. D. S. Carvalho, A. C. S. Fernandes, and D. D. A. Azevedo, "Molecular composition and paleobotanical origin of ambers from the Araripe basin, santana formation," Química Nova, vol. 32, no. 6, pp. 1528-1533, 2009.

[12] R. M. Maia, P. R. Barbosa, F. G. Cruz, N. F. Roque, and M. Fascio, "Triterpenes from the resin of protium heptaphyllum March (Burseraceae): characterization in binary mixtures," Química Nova, vol. 23, no. 5, pp. 623-626, 2000.

[13] D. M. Martill, "Fish oblique to edding in early diagenetic concretions from the cretaceous santana formation of Brazilimplications for substrate consistency," Palaeontology, vol. 40, no. 4, pp. 1011-1026, 1997.

[14] M. G. Taylor, S. F. Parker, K. Simkiss, and P. C. H. Mitchell, "Bone mineral: evidence for hydroxy groups by inelastic neutron scattering," Physical Chemistry Chemical Physics, vol. 3, pp. 1514-1517, 2001.

[15] S. Gunasekaran, G. Anbalagan, and S. Pandi, "Raman and infrared spectra of carbonates of calcite structure," Journal of Raman Spectroscopy, vol. 37, no. 9, pp. 892-899, 2006.

[16] I. Rehman and W. Bonfield, "Characterization of hydroxyapatite and carbonated apatite by photo acoustic FTIR spectroscopy," Journal of Materials Science, vol. 8, no. 1, pp. 1-4, 1997.

[17] K. Kandori, A. Yasukawa, and T. Ishikawa, "Preparation and characterization of spherical calcium hydroxyapatite," Chemistry of Materials, vol. 7, no. 1, pp. 26-32, 1995.

[18] R. M. Wilson, S. E. P. Dowker, and J. C. Elliott, "Rietveld refinements and spectroscopic structural studies of a Na-free carbonate apatite made by hydrolysis of monetite," Biomaterials, vol. 27, no. 27, pp. 4682-4692, 2006.

[19] A. O. Souza, M. C. Rangel, and O. L. Alves, "Synthesis and characterization of $\alpha$-zirconium (IV) hydrogenphosphate containing metallic copper clusters," Química Nova, vol. 28, no. 1, pp. 46-49, 2005.

[20] D. M. Martill, P. R. Wilby, and N. Williams, "Elemental mapping: a technique for investigating delicate phosphatized fossil soft tissues," Palaeontology, vol. 35, no. 4, pp. 869-874, 1992.

[21] D. M. Martill, "Preservation of fish in the Cretaceous Santana formation of Brazil," Paleontology, vol. 31, pp. 1-18, 1998.

[22] D. A. Grimaldi and J. Maisey, "Introduction In insect from the Santana Formatio, Lower Cretaceus of Brazil," in Bulletin of the American Museum of Natural History, D. A. Grimaldi, Ed., pp. 5-14, 1990.

[23] C. G. Mothé, H. F. Mothé Filho, and R. J. C. Lima, “Thermal study of the fossilization processes of the extinct fishes in Araripe Geopark," Journal of Thermal Analysis and Calorimetry, vol. 93, no. 1, pp. 101-104, 2008.

[24] M. S. Djosic, V. B. Miskovic-Stankovic, S. Milonjic, Z. M. Kacarevic-Popovic, N. Bibic, and J. Stojanovic, "Electrochemical synthesis and characterization of hydroxyapatite powders," Materials Chemistry and Physics, vol. 111, pp. 137-142, 2008. 
[25] F. E. Sousa Filho, J. H. Silva, A. A. F. Saraiva et al., "Combination of raman, infrared, and x-ray energy-dispersion spectroscopies and x-ray diffraction to study a fossilization process ," Brazilian Journal of Physics, vol. 41, pp. 275-280, 2011. 

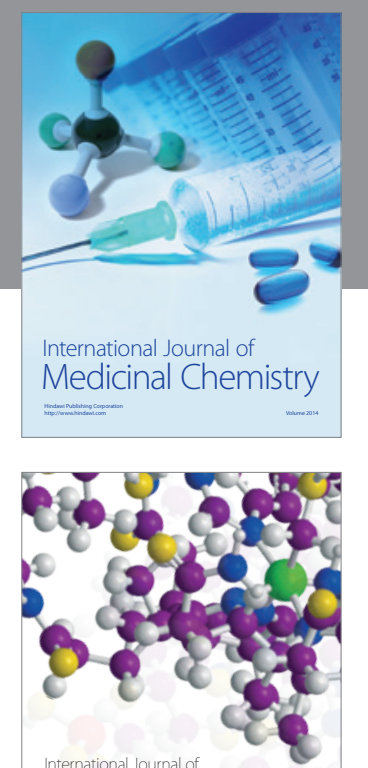

\section{Carbohydrate} Chemistry

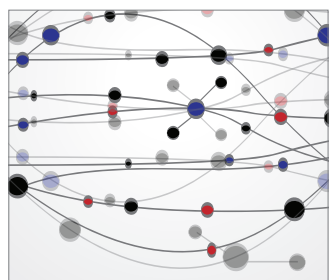

The Scientific World Journal
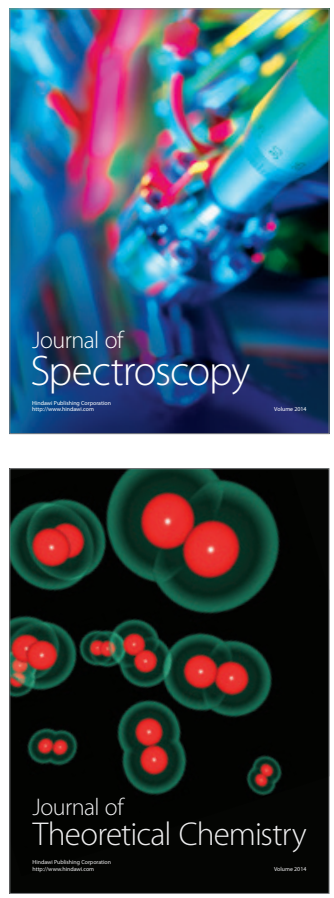
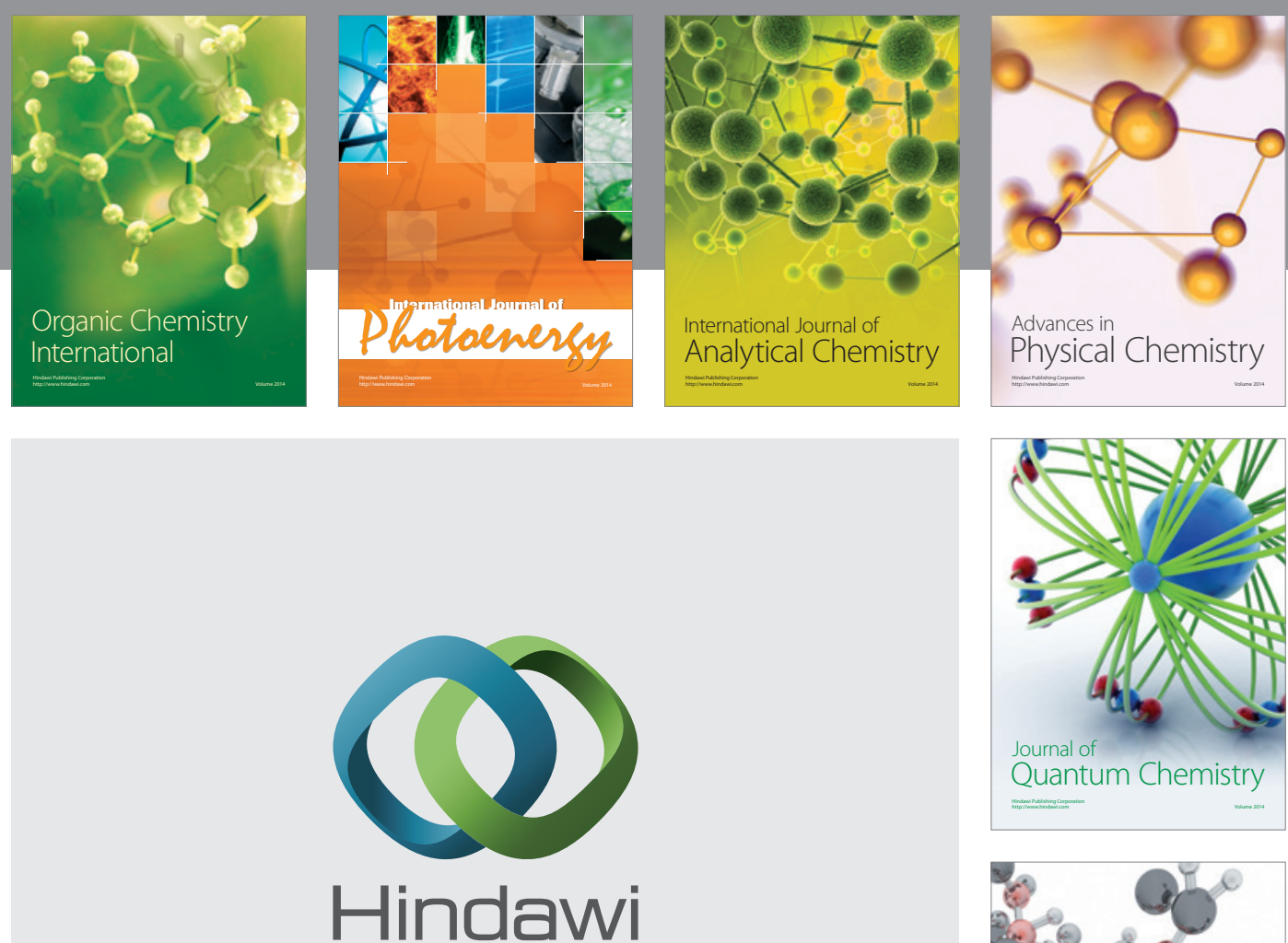

Submit your manuscripts at

http://www.hindawi.com

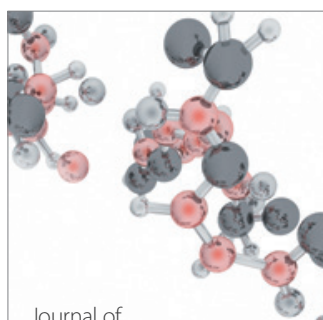

Analytical Methods

in Chemistry

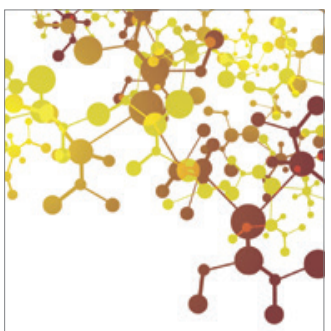

Journal of

Applied Chemistry

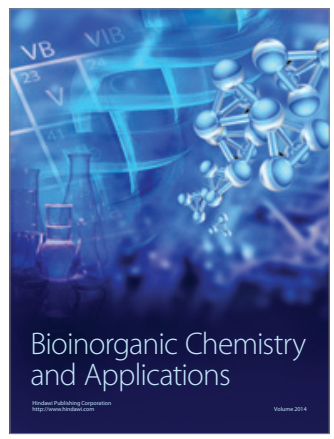

Inorganic Chemistry
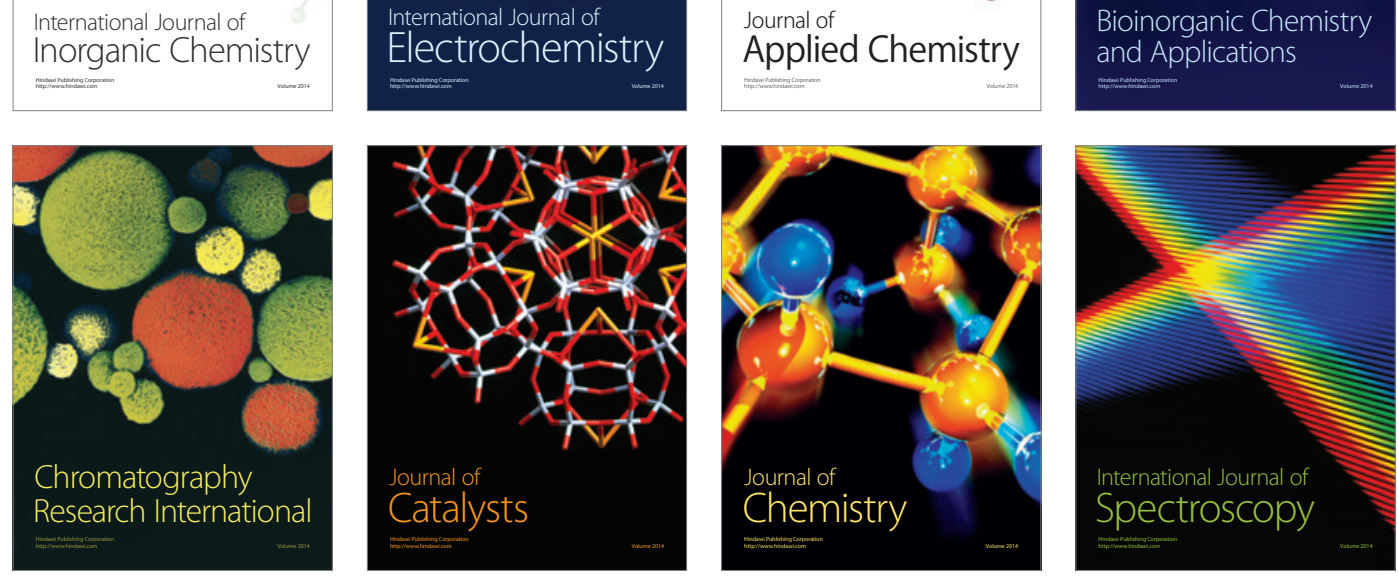